DOCTRINA

\title{
Privacidad en línea en la jurisprudencia constitucional chilena
}

\author{
Privacy online in the Chilean constitutional case law
}

\author{
Daniel Álvarez Valenzuela \\ Doctorando, Universidad de Chile
}

\begin{abstract}
RESUMEN Este artículo tiene por objeto revisar el estado actual de la protección de la privacidad de las personas en internet a partir del análisis de la jurisprudencia constitucional emanada tanto del Tribunal Constitucional como de la Corte Suprema y algunas cortes de Apelaciones del país relativa al derecho a la vida privada y al derecho a la inviolabilidad de toda forma de comunicación privada. Veremos cómo las prácticas más cotidianas de los usuarios de internet (el uso de correo electrónico, el intercambio de mensajes y la navegación) están siendo amparadas por la jurisprudencia constitucional más relevante, sin perjuicio de algunas sentencias que han negado la tutela por cuestiones meramente formales, a pesar de la especial protección que requieren estas formas de comunicación.
\end{abstract}

PALABRAS CLAVE Vida privada, comunicaciones electrónicas, Chile, jurisprudencia

\begin{abstract}
This article aims to review the current state of protection to people's privacy on the Internet, by analyzing the constitutional case law from the Chilean Constitutional Court, the Supreme Court, and some Courts of Appeal in Chile that have decided on the right to privacy and the right to inviolability of any form of private communication. It shows that daily activities of Internet users -such as using e-mail, texting, and online browsing- are protected by most relevant constitutional case law, but some court decisions deny protection because of mere formulary exigencies, despite the special protection required by these forms of communication under the constitutional rule.
\end{abstract}

KEYWORDS Privacy, electronic communications, Chile, cases law.

\section{Introducción}

Hasta fines del siglo pasado, las invasiones al derecho a la privacidad eran un asunto que confrontaban, por una parte, el interés legítimo de los medios de comunicación social de informar y ser parte del proceso de formación de la opinión pública —imprescindible en 
un Estado democrático-, y, por otro lado, los legítimos intereses de las personas cuya intimidad se veía expuesta, su imagen distorsionada o su buen nombre mancillado por la labor de esos medios de comunicación social (Zweigert y Kötz, 2002: 732).

En estos días, las amenazas contra uno de los más complejos derechos fundamentales - el derecho a la privacidad - no provienen únicamente de los medios de comunicación social. La masificación de las tecnologías, el uso intensivo de dispositivos electrónicos conectados a internet, el procesamiento de ingentes cantidades de datos personales e, incluso, la exposición voluntaria de los usuarios, han puesto en riesgo la protección de la privacidad de las personas y han desafiado las respuestas que ofrecen los sistemas jurídicos.

En Chile, el derecho a la vida privada (que es la forma utilizada por la Constitución para referirse al derecho a la privacidad) y la garantía de inviolabilidad de las comunicaciones privadas han sido objeto de una discusión doctrinal discreta y un desarrollo jurisprudencial menor. A partir del texto constitucional de 1980, que distinguió formalmente entre ambas garantías, y la reforma constitucional del año 2005, que eliminó la referencia a la protección de la vida pública de las personas, existe una incipiente doctrina sobre el alcance del derecho a la vida privada y sobre los contornos de la garantía de inviolabilidad de las comunicaciones privadas. ${ }^{1}$

En este artículo intentaremos hacernos cargo de analizar la escasa jurisprudencia que han venido desarrollando los tribunales superiores en ejercicio de sus facultades constitucionales y los criterios de resolución que de ella se desprende.

Para ello, en la primera sección revisaremos sintéticamente los conceptos de vida privada e inviolabilidad de las comunicaciones privadas, para luego, en la sección segunda, analizar, respecto de cada uno de los usos de internet que hemos definido como relevantes, las sentencias pronunciadas por el Tribunal Constitucional de Chile dictadas tanto en procesos de control de constitucionalidad preventiva (de acuerdo al numeral 1. ${ }^{\circ}$ del artículo 93 de la Constitución Política de la República) como en aquellos incoados en ejercicio de la acción de inaplicabilidad por inconstitucionalidad de un determinado precepto legal (de acuerdo al numeral $6 .^{\circ}$ del artículo 93 de la Constitución). Revisaremos, además, cómo la Corte Suprema y las cortes de Apelaciones del país han resuelto algunos de los asuntos sometidos a su conocimiento - generalmente a través del ejercicio de la acción de protección de garantías constitucionales-en estas materias.

Concluiremos dando cuenta de la contundente protección que la jurisprudencia constitucional ha dado a las comunicaciones privadas que se verifican a través de correos electrónicos, aplicando en extenso el estatuto de inviolabilidad consagrado en el numeral $5 .^{\circ}$ del artículo 19 de la Constitución. Asimismo, constaremos que respecto

1. Sobre este punto recomendamos revisar una de las obras más completas en castellano sobre el concepto de derecho a la vida privada, escrita por el profesor y jurista Eduardo Novoa Monreal durante su exilio en Venezuela y publicada en 1979: Derecho a la vida privada y libertad de información. Un conflicto de derechos. También véanse Vial (2000: 47-68), Anguita (2007), Corral Talciani (200oa: 51-79 y 20oob: 331-355) y, de fecha más reciente, Figueroa (2015). 
a las comunicaciones que se emiten por medio de redes sociales, la escasa jurisprudencia existente no ha sido capaz de resolver adecuadamente los problemas que se le han planteado y, a partir de análisis formalistas, ha negado la debida protección que estas novísimas formas de comunicación merecen. Por último, respecto a la navegación en internet, podemos sostener que la opinión mayoritaria del Tribunal Constitucional considera que el mero hecho de usar la red, sin perjuicio de ser un espacio abierto, constituye un acto que pertenece al ámbito de la vida privada de las personas, protegido por el numeral $4 \cdot^{\circ}$ del artículo 19 de la Constitución Política.

\section{Sobre la protección de la vida privada en la Constitución chilena}

El derecho a la vida privada constituye una de las innovaciones de la Constitución de 1980. Antes, en Chile se resguardaban el hogar, los papeles y la correspondencia privada, pero no existía en nuestro ordenamiento constitucional un derecho específico que protegiera las expresiones de la actividad humana que forman parte de aquello que denominamos intuitivamente como "privacidad», distinguiéndola del resguardo que se brindaba al hogar y a la correspondencia.

A partir del texto constitucional de 1980, que reconoció la protección de la vida privada como derecho independiente, y las reformas constitucionales del año 2005 (Ley 20.050, artículo 1, numeral 10. ${ }^{\circ}$, literal b), que eliminó la referencia la protección de la vida pública de las personas, y del año 2018 (Ley 21.986, artículo único), que agregó expresamente la protección de datos personales, en Chile contamos con un sistema de protección de la privacidad compuesto por cinco derechos perfectamente diferenciados entre sí, a saber:

- el derecho a la vida privada;

- el derecho a la protección de datos personales;

- el derecho a la inviolabilidad del hogar;

- el derecho a la inviolabilidad de las comunicaciones privadas; y,

- el derecho a la inviolabilidad de los documentos privados.

Estos derechos, en conjunto con las normas pertinentes de los tratados internacionales sobre derechos humanos suscritos y ratificados por Chile y que se encuentren vigentes, ${ }^{2}$ forman parte del denominado bloque constitucional ${ }^{3}$ de protección de la vida privada, que debe guiar, por una parte, las decisiones legislativas que buscan materia-

2. Declaración Universal de Derechos Humanos, 1948, artículo 12; Pacto Internacional de Derechos Civiles y Políticos, 1966, artículo 17; Convención Americana sobre Derechos Humanos, 1969, artículo 11; Declaración Americana de Derechos y Deberes del Hombre, 1948, artículos 5, 9 y 10.

3. El concepto doctrinario de bloque constitucional de derechos fundamentales fue recientemente reconocido, por primera vez, en la sentencia del Tribunal Constitucional rol 2493-13, del año 2013, considerandos séptimo y octavo. 
lizar y concretizar dicha protección, y, por otra, las decisiones judiciales que pretendan dar amparo efectivo en cada caso particular que se les presente. Para efectos de este artículo, únicamente nos referiremos a dos de los cinco derechos enunciados: el derecho a la vida privada y el derecho a la inviolabilidad de las comunicaciones privadas.

Una de las principales dificultades que ha experimentado la doctrina y la jurisprudencia nacional para el desarrollo de una teoría sobre el sistema constitucional de protección de la privacidad, ha consistido precisamente en definir el alcance de los conceptos en estudio y la determinación de los bienes jurídicos amparados por estos derechos. ${ }^{4}$ Responder la pregunta acerca de qué es la privacidad suele sacarnos a pasear por consideraciones de tipo social, cultural, históricas, antropológicas e, incluso, religiosas. ${ }^{5}$ Con todo, es posible constatar que salvo excepcionalísimos casos, la comprensión del derecho a la privacidad como expresión de la autodeterminación personal de los individuos, en la manera en que es entendida en el derecho estadounidense (Nieves Saldaña, 2011: 195-240), ${ }^{6}$ no ha sido desarrollada suficientemente entre nosotros (Figueroa, 2015: 129-153) ${ }^{7}$ e incluso autores como Corral Talciani niegan que se pueda comprender de esta manera (200oa: 348).

Una somera revisión de la doctrina nacional relativa al derecho consagrado en el numeral 4 del artículo 19, permite constatar el consenso que existe respecto a la dificultad de precisar qué se entiende por vida privada. Diversos autores coinciden en que por tratarse de un concepto de contornos indeterminados (Tapia, 2008: 137), de carácter cultural (Camacho, 2014: 76; Nogueira Alcalá, 2013: 769; Vial, 2000: 51; Vivanco, 1992: 219), variable en el tiempo (Nogueira Alcalá, 2013: 769) y en el espacio (Camacho, 2014: 76; Vial, 2000: 51; Vivanco, 1992: 219), la determinación de su alcance y la identificación de sus límites es una labor que le corresponde esencialmente a la jurisprudencia, sin perjuicio que algunos pocos de ellos se aventuren en la tarea de formular una definición más precisa (Barros, 2010: 536; Tapia, 2008: 137; Figueroa, 2015: 126).

Así, por ejemplo, a fines de la década de los setenta, Novoa Monreal afirmaba —con múltiples prevenciones- que la vida privada está

constituida por aquellos fenómenos, comportamientos, datos y situaciones de una persona que normalmente están sustraídos al conocimiento de extraños y cuyo conocimiento por estos puede turbarla moralmente por afectar su pudor o su recato, a menos que esa misma persona asienta a ese conocimiento (1979: 49).

4. Undurraga (2005: 509) sostiene un interesante debate sobre la privacidad como bien jurídico rebatiendo las aproximaciones de Corral Talciani (2000a y 20oob).

5. Novoa Monreal (1979) entrega una visión general sobre el derecho a la vida privada.

6. Desde un punto de vista constitucional, el derecho estadounidense otorga una amplia protección al derecho a la vida privada, entendida como autonomía individual o autodeterminación personal, que ha permitido el desarrollo de una interesante jurisprudencia constitucional que ha puesto límites a la capacidad normativa del Estado respecto de las conductas de las personas. Una excelente explicación sobre la génesis y alcance del right to privacy en el derecho norteamericano se encuentra en la obra citada.

7. La obra a que se hace referencia otorga una visión general de la privacidad como autonomía. 
Recién dictado el nuevo texto constitucional, López Santamaría precisaba que la vida privada estaría compuesta por «las circunstancias cuyo conocimiento el interesado normalmente sólo está dispuesto a compartir con sus parientes y amigos» (1982: 67), situándola en medio de la vida íntima y la vida pública.

Ya en este siglo, Vial define el derecho a la vida privada como

aquel derecho que está destinado a proteger la dignidad y libertad humana, por medio del reconocimiento de su titular de un poder de control sobre su ámbito privado, que en su núcleo central se identifica con el cuerpo y la afectividad, y respecto la información relativa a la persona (2000: 68).

Recientemente, Figueroa ha propuesto una noción del derecho a la privacidad «como el derecho a que un tercero no intervenga el cuerpo, objetos personales o lugares relacionados con el titular, si este no lo ha autorizado» (2015: 126).

Desde una perspectiva civil, Barros (2010: 548-576) identifica los intereses protegidos reconocibles en el derecho chileno:

- la privacidad como un ámbito físico de intangibilidad;

- la privacidad como deber de reserva o confidencialidad;

- la privacidad como secreto;

- la privacidad como bien moral y comerciable; $y$,

- la privacidad en el tratamiento de datos personales.

Excluye Barros la autodeterminación o autonomía individual como interés protegido, sin explicar mayormente las razones.

Por nuestra parte, consideramos que es posible conceptualizar el derecho a la vida privada como aquel derecho que ampara los ámbitos de la vida de un sujeto determinado que, por su decisión o por mandato de la ley, quedan fuera del conocimiento o alcance de terceros y del Estado. Así, sus preferencias sexuales, políticas o religiosas, sus hábitos personales, sus decisiones de consumo, su cuerpo y las decisiones que sobre él recaen, por mencionar algunos aspectos, se encuentran fuera del conocimiento general o de la intervención estatal.

\section{Sobre la inviolabilidad de las comunicaciones privadas en Chile}

La protección de la inviolabilidad de los papeles y de la correspondencia privada tiene una larga tradición en el derecho constitucional chileno. Ya en los primeros textos constitucionales se resguardaba — además del hogar y los papeles-la correspondencia epistolar. Así, por ejemplo, la Constitución de $1818^{8}$ establecía que la «correspondencia epistolar» y los "papeles» de los ciudadanos eran sagrados y solo procedía su interceptación cuando «la salud general y bien del Estado» así lo exigiera. En la Carta Fun-

8. Promulgada el 8 de agosto de 1818, bajo el mandato de Bernardo O’Higgins. 
damental de 1833 se estableció la estructura normativa que expresamente reconoce la inviolabilidad de la correspondencia epistolar, a partir de una fórmula lingüística que ha pervivido hasta nuestros días ${ }^{9}$ a través de su reproducción en Constitución de $1925^{10}$ y la actualización en el texto de 1980.

De esta manera, la estructura actual del derecho a la inviolabilidad se configura por la evolución de las normas constitucionales desde 1812 a la fecha, destacándose los textos de 1822,1828 y 1833 , y la clara influencia recibida de sistemas jurídicos tan diversos como el norteamericano y el francés (Álvarez Valenzuela, 2018). Es un derecho fundamental de larga data en nuestro sistema constitucional, autónomo e independiente de la protección que se brinda a la vida privada en la Constitución, cuestión que se desprende de su historia, de su consagración textual diferenciada y de razones sustanciales.

La regla vigente recoge la experiencia acumulada en los doscientos años de historia constitucional chilena, utilizando la estructura que la Constitución de 1833 propuso para la protección de la correspondencia epistolar, ampliando el ámbito de aplicación al concepto genérico de "comunicación privada», que reconoce al acto comunicativo en sí mismo como objeto de amparo constitucional, con independencia del soporte utilizado para materializar tal acción comunicativa y, lo que resulta más importante, con prescindencia del contenido de la comunicación.

La Constitución vigente protege por igual una comunicación privada donde se expongan aspectos sensibles de la vida de las personas o aquellas donde se expongan nimiedades o asuntos sin importancia. Esta innovación, que parece menor, resulta de singular importancia atendido los efectos que genera en la construcción de una garantía constitucional de carácter autónomo e independiente del derecho a la vida privada reconocido en el numeral 4 del mismo artículo 19.

Cuando la Constitución decide proteger el acto comunicacional privado en sí mismo, más allá de su forma de exteriorización, establece un objeto de protección muchísimo más amplio que los textos constitucionales precedentes.

Respecto del carácter "privado» de una comunicación, en la doctrina nacional Cea (2004: 195) ha sostenido que lo privado es aquello que está destinado solo al conocimiento de emisor y receptor «y no del público ni de terceros más circunscritos». Por su parte, Vivanco (2006: 397) afirma que serían aquellas «comunicaciones restringidas entre dos o más personas y, por tanto, no están destinadas al dominio público». Como es evidente, el concepto de privado suele definirse por oposición a lo público. Así lo hizo, también, la Comisión de Estudios de la Nueva Constitución (CENC), en la sesión 129, cuando afirmó, en opinión del consejero Guzmán, que «al decir "privadas” el concepto se circunscribe obviamente a las comunicaciones que no son públicas» (BCN, 2008: 339).

9. El artículo 138 establecía: «La correspondencia epistolar es inviolable. No podrá abrirse, ni interceptarse, ni registrarse los papeles o efectos, sino en los casos expresamente señalados en la ley».

10. Artículo 10. «La Constitución asegura a todos los habitantes de la República: 13. La inviolabilidad de la correspondencia epistolar y telegráfica. No podrán abrirse, ni interceptarse, ni registrarse los papeles o efectos públicos, sino en los casos expresamente señalados por la ley.» 
Para Nogueira Alcalá (2013: 931), el carácter de privado de una comunicación viene dado por la determinación precisa de los destinatarios de ésta, quienes serán los únicos autorizados para recibirla, quedando excluidos los terceros o el público en general. Mohor (2013: 321) sostiene, ahondando en el mismo criterio, que una comunicación es privada cuando la «transmisión de datos o mensajes [es] dirigida precisamente a uno o más destinatarios determinados, con exclusión de cualquier otra persona».

De esta manera, para efectos del numeral $5 .^{\circ}$ del artículo 19 de la Constitución, lo «privado» es aquello que no va dirigido al público. Lo «privado» es aquello que va dirigido determinadamente a uno o varios receptores seleccionados por el emisor, con el propósito de que sólo él o ellos lo reciban. Lo privado, entonces, es un concepto que se vincula con las características del acto comunicativo decididas por el emisor de la comunicación, quien es, en definitiva, quien determinará si la expresión comunicativa que va a realizar reviste la calidad de comunicación privada. El contenido, por tanto, es irrelevante y permite distanciarlo de la idea de «vida privada» utilizada por la Constitución en el numeral $4 .^{\circ}$ del artículo 19.

De esta manera, en nuestra opinión, el concepto de «comunicaciones privadas» utilizado en el numeral 5 del artículo 19 de la Constitución se refiere a toda comunicación que se proyecta de una persona hacia otra (que pueden ser una o varias personas) que ha sido escogida por el emisor y donde no importa el contenido ni el medio por el cual se materialice la comunicación. ${ }^{11}$

Como veremos a continuación, los correos electrónicos intercambiados y los mensajes enviados vía Whatsapp o Telegram, junto a la utilización de internet, el trazado de sitios visitados, las conversaciones sostenidas, la experiencia compartida en redes sociales, son algunas de las expresiones de la actividad humana que forman parte de aquello que denominamos genéricamente como vida privada y que son objeto de la protección del mencionado bloque constitucional.

\section{Jurisprudencia constitucional}

A continuación revisaremos cuáles han sido los criterios utilizados en diversas decisiones jurisdiccionales tanto de la Corte Suprema y de las cortes de Apelaciones, como del Tribunal Constitucional, órgano que se ha pronunciado en a lo menos diez ocasiones sobre el derecho a la vida privada ${ }^{12}$ y en ocho sobre el derecho a la inviolabilidad de las comunicaciones privadas. ${ }^{13}$ Conforme al objetivo del presente artículo, únicamente analizaremos aquellas sentencias que contengan algún elemento o criterio relevante a

11. En Álvarez Valenzuela (2004: 195) observamos una versión previa de este concepto.

12. Sentencias del Tribunal Constitucional roles 389-03, 433-05, 521-06, 1365-09, 1683-10, 1732/1800-10, 1894-11, 1939-11 y 1990-11.

13. Sentencias del Tribunal Constitucional roles 198-94, 389-03, 433-05, 2153-11, 2246-12, 2379-12, 2689-14 y 2982-16. 
la luz del desarrollo tecnológico ${ }^{14}$ y que se refieran a tres prácticas comunes y cotidianas de los usuarios de internet:

- uso del correo electrónico;

- servicios de mensajería instantánea; y,

- navegación por internet.

\section{Uso de correo electrónico}

Hoy es un hecho innegable que buena parte de las comunicaciones personales profesionales se llevan a cabo a través del correo electrónico, desplazando así a las formas tradicionales de comunicación analógicas que dominaron el siglo pasado: el teléfono y la correspondencia postal. El correo electrónico es una forma de comunicación persona a persona, donde el emisor escoge al o los destinatarios y que se transmite electrónicamente a través de internet. De esta manera, sólo aquellas personas singularizadas por el emisor pueden acceder legítimamente a la comunicación y a su contenido, no importando si la comunicación se realiza o no por canales encriptados. ${ }^{15}$

Cabe entonces preguntarse si este tipo particular de comunicación personal califica como "comunicación privada», como la amparada por la Constitución Política. Para responder esta pregunta recurriremos a las contundentes sentencias del Tribunal Constitucional ${ }^{16}$ dictadas con ocasión de los conflictos que se suscitaron por sendas decisiones del Consejo para la Transparencia (roles C1101-11, 2012; y C-40611, 2011) ${ }^{17} \mathrm{de}$ exigir la revelación de los correos electrónicos enviados y recibidos por ciertas autoridades públicas en el ejercicio de sus cargos.

El Tribunal Constitucional precisó el alcance de la garantía de inviolabilidad de las comunicaciones privadas, afirmando de manera categórica que los correos electrónicos «son comunicaciones y documentos privados, en el lenguaje del artículo 19 número 5 de la Constitución. Por lo mismo, están protegidas por este derecho». ${ }^{18}$

El Tribunal fundamenta su decisión en las siguientes consideraciones:

a) La Constitución protege «toda» forma de comunicación privada, precisamente para no excluir ninguna, avanzando respecto a constituciones anteriores que protegían

\footnotetext{
14. Para un análisis de la evolución de la jurisprudencia del Tribunal Constitucional sobre protección de datos personales, véase Quezada (2012: 125-147). Para una categorización de la jurisprudencia de protección sobre derecho a la privacidad, pero limitada hasta el año 2010, véase Figueroa (2015).

15. Para una descripción técnica del correo electrónico, véase Rodríguez (2003: 193-209).

16. Sentencias del Tribunal Constitucional roles 2153-2011 y 2246-2012, entre otras.

17. Estas decisiones fueron recurridas de ilegalidad ante la Corte de Apelaciones de Santiago, gestiones que dieron origen a las solicitudes de declaración de inaplicabilidad por inconstitucionalidad del inciso segundo del artículo $5^{\circ}$ de la Ley No 20.285 sobre acceso a la información pública, ante el Tribunal Constitucional.

18. Sentencia del Tribunal Constitucional rol 2153-2011, considerando vigésimo noveno.
} 
ciertos tipos de comunicaciones: «papeles» en las cartas de 1812 y 1818 o «correspondencia» en los textos de 1833 y $1925 .^{19}$

Siguiendo la opinión de la doctrina nacional, se buscó proteger «toda forma de comunicación intelectual y espiritual entre dos individuos, por cualquier medio que se hiciera» (considerando trigésimo). ${ }^{20}$ En este sentido, podemos agregar que la norma constitucional es tecnológicamente neutra, por cuanto no exige que la comunicación se verifique por alguna forma o por algún medio específico; lo que importa es el acto comunicativo en sí mismo. En palabras del Tribunal, «el precepto comprende las formas actuales y las futuras de comunicaciones, incluido, por cierto, el correo electrónico» (considerando trigésimo).

Esta declaración tiene especial relevancia respecto de las nuevas formas de comunicaciones que hoy se verifican a través de redes sociales o plataformas híbridas de intercambio de información, como los mensajes directos de Twitter, mensajes personales de Facebook o los grupos de Whatsapp, que, como veremos más adelante, también se encuentran bajo el amparo de la garantía de inviolabilidad.

b) La Constitución asegura la «inviolabilidad» de las comunicaciones privadas que protege simultáneamente dos bienes jurídicos:

La libertad de las comunicaciones, porque el mero hecho de saber que una comunicación privada podrá ser interceptada o registrada, inhibiría en los sujetos el deseo de comunicarse, afectando su libertad; $y$,

El secreto de las comunicaciones, precaviendo que terceros ajenos accedan a la comunicación (considerando trigésimo primero).

Respecto del secreto, el Tribunal Constitucional es bastante categórico al afirmar que la inviolabilidad protege la comunicación en sí misma, independiente de su contenido, constituyendo una

presunción iuris et de iure de que lo que se transmite es parte de la privacidad de las personas, por lo que la revelación de ello, independientemente de su contenido, vulnera el derecho de la privacidad (considerando trigésimo primero)

Descartando así las argumentaciones que sostenían que para calificar de "privada» una comunicación, debía estarse al contenido de la comunicación, calificación que realizaría un tercero ajeno, afectándose por ese solo acto la inviolabilidad de la comunicación (cf. considerando trigésimo primero de la misma sentencia).

Como se aprecia, el Tribunal construye un argumento donde relaciona la inviolabilidad de las comunicaciones privadas y el derecho a la vida privada, protegiendo la primera garantía el acto comunicativo en sí mismo y el contenido de la comunicación, la segunda, dando aplicación específica al bloque constitucional de protección de la vida privada.

19. Sentencia del Tribunal Constitucional rol 2153-2011, considerando trigésimo.

2o. Hace referencia a una cita extraída del Tratado de Derecho Constitucional del profesor Alejandro Silva Bascuñán (en específico, a la página 204 del tomo XI) 
Al protegerse la comunicación en sí misma, se está protegiendo el mensaje (continente y contenido) pero también los datos de tráfico, como expresamente señaló el Tribunal en la citada sentencia:

Lo que esta garantía protege es la comunicación, cualquiera sea su contenido y pertenezca o no éste al ámbito de la privacidad o intimidad. El secreto se predica respecto de la comunicación. Por lo mismo, abarca el mensaje y los datos de tráfico (ruta, hora, fecha, sujetos, etc.). (considerando trigésimo primero)

Al mencionar los datos de tráfico, el Tribunal está fijando el alcance de la garantía de inviolabilidad y determinando los límites para la aplicación e interpretación de las disposiciones legales que regulan las intromisiones legítimas; esto es, aquellas que sean expresamente establecidas en la ley, que cumplan con los estándares de especificidad y determinación y que no afecten la esencia del derecho protegido (cf. STC rol 325-2001, considerando cuadragésimo). ${ }^{21}$

En nuestro sistema jurídico, la interceptación, apertura o registro de comunicaciones privadas está contenida, principalmente, en los artículos 218 y siguientes del Código Procesal Penal y en ciertas disposiciones de leyes especiales ${ }^{22}$ que regulan los casos, formas y requisitos que se deben cumplir para levantar la inviolabilidad de las comunicaciones privadas, no refiriéndose de manera específica a los datos de tráfico, salvo el registro de conexiones IP contenidas en el artículo 222 de Código Procesal Penal de la República de Chile. ${ }^{23}$

c) La Constitución asegura la inviolabilidad de las comunicaciones «privadas», esto es, aquellas donde el emisor «singulariza al o los destinatarios de su comunicación, con el evidente propósito de que sólo él o ellos la reciban» (Sentencia del Tribunal Constitucional rol 2153-2011, 2012: considerando trigésimo quinto), ${ }^{24}$ excluyendo de su conocimiento a terceros ajenos a ella.

21. " $40^{\circ}$. Que, en este sentido, es necesario reiterar el criterio que ha sostenido este tribunal en cuanto a que las disposiciones legales que regulen el ejercicio de estos derechos, deben reunir los requisitos de 'determinación' y 'especificidad'. El primero exige que los derechos que puedan ser afectados se señalen, en forma concreta, en la norma legal; y el segundo requiere que la misma indique, de manera precisa, las medidas especiales que se puedan adoptar con tal finalidad. Por último, los derechos no podrán ser afectados en su esencia, ni imponerles condiciones, tributos o requisitos que impidan su libre ejercicio»

22. Ley 18.314, 1984; Ley 19.927, 2004; Ley 19.974, 2004; Ley 20.000, 2005; Decreto Ley 211, 1973; Ley 21.000, 2017.

23. "Las empresas telefónicas y de comunicaciones deberán dar cumplimiento a esta medida, proporcionando a los funcionarios encargados de la diligencia las facilidades necesarias para que se lleve a cabo con la oportunidad con que se requiera. Con este objetivo los proveedores de tales servicios deberán mantener, en carácter reservado, a disposición del Ministerio Público, un listado actualizado de sus rangos autorizados de direcciones IP y un registro, no inferior a un año, de los números IP de las conexiones que realicen sus abonados.»

24. Hace referencia al texto ya referido de Alejandro Silva Bascuñán, ahora en relación con la página 205 del mismo. Este considerando se encuentra reiterado de manera textual en (Sentencia del Tribunal Constitucional rol 2246-2012, 2013, considerando quincuagésimo primero) 
En nuestra opinión, el concepto de comunicación privada alcanza toda comunicación que se proyecta de una persona hacia otra (que pueden ser una o varias personas) que ha sido escogida por el emisor y donde no importa el contenido ni el medio por el cual se materialice la comunicación.

En el ámbito de internet, por ejemplo, serían comunicaciones privadas los mensajes enviados a través de grupos cerrados de Whatsapp o a través de sistemas de comunicaciones internas de redes sociales como Twitter, Facebook o Linkedin, que evidentemente van dirigidas al o los destinatarios seleccionados individual o grupalmente por el emisor del mensaje.

En el caso de las comunicaciones que se realizan a través de publicaciones «abiertas» al colectivo de miembros de una red como Facebook, por ejemplo, en el denominado «muro», en principio no estaríamos ante una comunicación privada en los términos que exige la Constitución. De hecho, el Tribunal Constitucional considera que un elemento central en la protección de esta garantía consiste precisamente en el carácter «cerrado» de la comunicación. ${ }^{25}$ No obstante lo anterior, existen hipótesis en las cuales podrían calificar como tales las comunicaciones que se realicen en el muro de Facebook, cuando las circunstancias permitan sostener que su titular tiene una expectativa razonable de privacidad. ${ }^{26}$ Sobre este punto, volveremos más adelante.

En base a estas tres argumentaciones principales, el Tribunal Constitucional ha resuelto $^{27}$ que los correos electrónicos son comunicaciones privadas, amparadas por la garantía de inviolabilidad cuya interceptación, registro o apertura solo procede en los casos expresamente establecidos en la ley. En palabras del Tribunal:

El acceso a comunicaciones privadas sólo puede permitirlo el legislador cuando sea indispensable para una finalidad de relevancia mayor; cuando no haya otra alternativa disponible; bajo premisas estrictas; con una mínima intervención y nunca de manera constante y continua, sino que de forma limitada en el tiempo y siempre de modo específico, señalándose situaciones, personas, hechos (Sentencia del Tribunal Constitucional rol 2153-2011, considerando cuadragésimo primero).

Configurado el alcance de la interpretación constitucional de la regla de inviolabilidad, cabe repasar algunas de las decisiones más importantes, y no necesariamente las más afortunadas, de la Corte Suprema y las Cortes de Apelaciones, al momento de conocer y resolver las acciones de protección relativas al uso del correo electrónico y su protección por la garantía de inviolabilidad del numeral 5 del artículo 19 de la Constitución. Revisemos algunos de estos casos.

25. Cf. Sentencia del Tribunal Constitucional rol 2153-2011, considerando trigésimo quinto. Este considerando se encuentra reiterado de manera textual en Sentencia del Tribunal Constitucional rol 2246-2012, 2013, considerando quincuagésimo primero.

26. Salvo aquellos usuarios que han configurado un alto nivel de privacidad en sus respectivas cuentas de Facebook, que les permite mantener un control más estricto respecto de los destinatarios de las comunicaciones o publicaciones que realizan. Esta hipótesis, la revisaremos más adelante.

27. Estos criterios fueron reiterados en la Sentencia del Tribunal Constitucional rol 2246-2012. 


\section{Anguita Ramírez con Jueza de Familia de Viña del Mar}

En un procedimiento de divorcio culpable, una de las partes ofreció como prueba de la infidelidad matrimonial más de sesenta correos electrónicos intercambiados entre su cónyuge y terceros, los que habrían sido obtenidos por medios ilícitos, cuestión que se alegó en la respectiva audiencia ante la jueza recurrida, quien resolvió admitirlos como prueba documental.

Interpuesta la acción de protección, la Corte de Apelaciones de Valparaíso la acogió argumentando que, habiéndose acreditado el acceso no autorizado a los correos electrónicos,

el ámbito íntimo es por esencia personalísimo, por lo que toda forma de comunicación privada es y debe ser respetada por todos. El incurrir en infracción a la observancia y reconocimiento de la señalada garantía constitucional, importa que tal acción u omisión es ilegal. ${ }^{28}$

La Corte desestimó así la alegación de una de las partes que sostenía que no estando sancionado penalmente el registro o apertura no autorizado de correspondencia entre cónyuges, como establece el artículo 146 inciso segundo del Código Penal de la República de Chile, ${ }^{29}$ no habría actuación ilegal que reprochar.

$\mathrm{Al}$ respecto, cabe señalar que la citada norma penal únicamente establece una circunstancia legal absolutoria a favor de los cónyuges y no constituye, bajo ninguna circunstancia, habilitación legal para la intromisión en las comunicaciones privadas del otro cónyuge. Reconocerle un sentido distinto a dicha disposición implicaría una afectación del derecho a la inviolabilidad de las comunicaciones privadas, que daría pie para impugnar su aplicación en el caso particular a través del ejercicio del recurso de inaplicabilidad por inconstitucionalidad ante el Tribunal Constitucional.

Lamentablemente, la Tercera Sala de la Corte Suprema (Sentencia de la Corte Suprema de Justicia rol 4135-2008, 2008) revocó la sentencia recurriendo a un argumento meramente formal: la conducta cuestionada es una decisión judicial, la que no puede ser impugnada por la vía cautelar, sin entrar a analizar el fondo de la cuestión debatida.

28. Sentencia de la Corte de Apelaciones de Valparaíso rol 208-2008, considerando sexto.

29. «Art. 146. El que abriere o registrare la correspondencia o los papeles de otro sin su voluntad, sufrirá la pena de reclusión menor en su grado medio si divulgare o se aprovechare de los secretos que ellos contienen, y en el caso contrario la de reclusión menor en su grado mínimo.

Esta disposición no es aplicable entre cónyuges, ni a los padres, guardadores o quienes hagan sus veces, en cuanto a los papeles o cartas de sus hijos o menores que se hallen bajo su dependencia.

TAMPoco es aplicable a aquellas personas a quienes por leyes o reglamentos especiales, les es lícito instruirse de correspondencia ajena.» 


\section{Humphreys Rivera con Centro de Ex Cadetes y Oficiales de la Armada «Caleuche»}

El Centro de Ex Cadetes y Oficiales de la Armada «Caleuche» decretó la expulsión de uno de sus socios, el recurrente, por las opiniones críticas que éste realizó en contra del Directorio, contenidas en un correo electrónico que erróneamente el destinatario reenvío a un miembro del mencionado directorio, quien no obstante recibir un nuevo mensaje electrónico advirtiéndosele del carácter privado del contenido del correo, lo divulgó.

La Corte de Apelaciones de Santiago rechazó, en lo pertinente, la acción de protección interpuesta, realizando una interpretación restrictiva de la garantía de inviolabilidad de las comunicaciones privadas. Sostuvo la Corte que, no habiéndose enmarcado la conducta de los recurridos en ninguna de las acciones contempladas en el texto constitucional, esto es, no «interceptaron», «abrieron» ni «registraron» el correo electrónico fuente de la información, no podría haber afectación del derecho (Sentencia de la Corte de Apelaciones de Santiago rol 22825-2011, 2012).

La Corte Suprema acogió la acción de protección y rechazó la interpretación de la Corte de Apelaciones, sosteniendo que «no se entregaría una real protección a nivel constitucional a las comunicaciones privadas si únicamente se las protegiera de su interceptación ilícita» (Sentencia de la Corte de Apelaciones de Santiago rol 22825-2011, 2012: considerando cuarto). Sostuvo que

el artículo 19 número 5 de la Constitución Política de la República garantiza la inviolabilidad de toda forma de comunicación privada, en el sentido de que éstas sólo pueden ser conocidas por las personas que intervienen en ella y no por personas ajenas que no han sido partícipes de ésta (Sentencia de la Corte de Apelaciones de Santiago rol 22825-2011, 2012: considerando tercero)

La apropiación de una comunicación privada y la utilización de su contenido por un tercero ajeno (en este caso, un tercero que accedió por error a la comunicación) es igualmente atentatoria contra la garantía de inviolabilidad de las comunicaciones privadas y contra el derecho a la vida privada que protege «la intimidad y ella no es sino una manifestación de la libertad en la esfera privada, cuya defensa comprende toda perturbación ilegítima de terceros» (Sentencia de la Corte de Apelaciones de Santiago rol 22825-2011, 2012: considerando cuarto).,

No es necesario entonces que se realicen acciones específicas de «interceptación», «apertura»o «registro» de comunicaciones privadas para que se afecte la garantía de inviolabilidad; basta cualquier forma de acceso o «uso indebido de una comunicación desplegada por el afectado dentro un entorno claramente acotado» (Sentencia de la Corte de Apelaciones de Santiago rol 22825-2011, 2012: considerando quinto).

Tal sería el caso, por ejemplo, de los correos electrónicos que, conteniendo declaraciones o avisos de confidencialidad respecto de su contenido, son reenviados a terceros ajenos a la conversación, contraviniendo así el «entorno claramente acotado» que definió su emisor. En esta hipótesis, también se estaría afectando el derecho a la invio- 
labilidad de las comunicaciones privadas, siguiendo el criterio definido por la Corte Suprema en esta sentencia.

Como es posible apreciar, la jurisprudencia constitucional no ha dudado en extender la protección constitucional de la inviolabilidad de las comunicaciones privadas a los correos electrónicos, afirmando que constituyen «comunicaciones y documentos privados» en el lenguaje del numeral $5 .^{\circ}$ del artículo 19 de la Constitución, objeto de protección explícito de la citada garantía, cuestión que debiera comenzar a ser recogida por la jurisprudencia especializada y por los tribunales de primera y segunda instancia.

\section{Comunicaciones en redes sociales}

Si el correo electrónico fue una herramienta disruptiva de la manera de comunicarse a partir del surgimiento de internet a mediados de los noventa, el uso intensivo de plataformas de intercambio de mensajería que ha provocado la masificación de los teléfonos inteligentes entre la población más joven ha llevado que estos consideren al correo electrónico como una herramienta obsoleta y anacrónica.

Hoy es común observar como personas o grupos de amigos se comunican a través de mensajes individuales y colectivos utilizando aplicaciones como Whatsapp, Telegram, Signal u otras similares. En éstas, los usuarios eligen a los destinatarios de sus mensajes - que pueden ser una o varias personas-generando un espacio de conversación -que puede ser en tiempo real o en diferido-compartido únicamente por quienes recibieron la comunicación inicial o fueron invitados posteriormente a ella. Sin duda alguna, se trata de comunicaciones privadas en los términos del numeral $5 .^{\circ}$ del artículo 19 de la Constitución y su interceptación, registro o apertura solo puede verificarse en los casos expresamente contemplados en la ley, tal como vimos anteriormente.

Lo mismo sucede con los mensajes intercambiados en sitios como Facebook, Twitter o Linkedin, que brindan al usuario la oportunidad de comunicarse «internamente» con otro usuario, sin necesidad de utilizar para ello los espacios públicos o abiertos del sitio. En el caso específico de Twitter, los mensajes directo ${ }^{30}$ pueden ser enviados únicamente a un usuario específico, quien será el único habilitado para abrirlo.

Como ya anticipamos, en el caso de las comunicaciones que se realizan a través de publicaciones «abiertas» al colectivo de miembros de una red social, en principio no estaríamos ante una comunicación privada en los términos que exige la Constitución, salvo que, por las especiales características de configuración de la red social, los destinatarios probables de la comunicación sean determinados o determinables. Sería el caso, por ejemplo, de un usuario de Facebook que ha configurado las opciones de privacidad que el sitio le ofrece de manera que sólo quienes expresamente ha aceptado como parte de su red, puedan ver y comentar las publicaciones que realice. En la misma situación se encuentra el usuario de Twitter que establezca la modalidad cerrada o «con

30. También conocidos como «DM» por las siglas en inglés de «Direct Messages». 
candado», en la cual debe autorizar previa y expresamente a los usuarios que podrán acceder a sus publicaciones.

En ambas hipótesis, resulta necesario analizar si es posible considerar que el usuario emisor de los mensajes tiene una expectativa razonable de privacidad, cuestión que obedece tanto a criterios prácticos como normativos.

Un primer criterio que puede ser útil para calificar cuán razonable es la expectativa de privacidad de un usuario de Facebook sería el número de «amigos» que ha consentido expresamente en que sean parte de su red de contactos. Un usuario que mantenga un nivel de control adecuado de su privacidad, y que tenga un número acotado de contactos, podría calificar su «muro» como un espacio donde no solo se llevan a cabo comunicaciones privadas sino que, además, donde ejecuta «específicos actos con la inequívoca voluntad de sustraerlos a la observación ajena» (Sentencia del Tribunal Constitucional rol 1894-2011, 2011: considerando vigésimo tercero). ${ }^{31}$ En cambio, un usuario cuya configuración de privacidad es más laxa, difícilmente pueda sostener que aquello que publica constituye una comunicación privada inviolable, lo que no obsta a que sí puede ser calificado como un acto de su vida privada, protegido en este caso por el numeral $4 .^{\circ}$ del artículo 19 de la Constitución.

Un segundo criterio que ayuda a determinar cuán razonable es la expectativa de privacidad de un sujeto es conocer su voluntad. Siguiendo la doctrina clásica del Tribunal Constitucional, ${ }^{32}$ que sostiene que la privacidad es expresión de la dignidad y libertad humana, depende de la voluntad del sujeto determinar si el acto comunicativo de que se trata forma o no parte de su esfera de privacidad. Así, si un usuario de Facebook o de Twitter cree razonablemente que sus publicaciones (o comunicaciones) solo pueden ser accedidas por el grupo reducido o controlado de usuarios que forman parte de su red, esto es, aquellos a quienes ha consentido expresamente formen parte de ella, eventualmente podría sostenerse que estamos ante un tipo especial de comunicación privada que, si bien es abierta para ese grupo específico de personas, es cerrada para el resto de los usuarios de la red social respectiva y para todos aquellos que no son parte de la red, estando por tanto protegida por la garantía de inviolabilidad y por el derecho a la vida privada.

Este es precisamente el criterio seguido por el voto disidente en Figueroa Silva con Prefecto de la Prefectura Cautín, acción de protección interpuesta por un carabinero que fue dado de baja por publicar en su «muro» de Facebook un comentario ofensivo contra un superior, el cual habría sido obtenido de manera ilegítima y allegado a la

31. Sobre la expectativa de privacidad en el espacio público, Novoa Monreal (1979: 203) sostiene que ciertos hechos o actitudes de las personas de carácter privados que no obstante desarrollarse en lugares públicos pueden ser calificados como privados cuando son realizados en ciertas condiciones que, a su juicio, las ponen en resguardo de la observación ajena, como en la oscuridad de la noche o en un rincón apartado y poco visitado.

32. Desarrollado por primera vez en la sentencia rol 389-2003, considerando decimoctavo, reafirmado en la sentencia rol 521-2006, considerando decimonoveno y en la sentencia rol 1894-2011, considerando vigésimo. 
investigación por la División de Inteligencia de Carabineros. El ministro de la Corte Suprema, Sergio Muñoz Gajardo, en el voto disidente sostiene:

Que cabe precisar que Facebook es un sitio web que permite a sus usuarios el poder comunicarse e intercambiar opiniones entre ellos, para lo cual el interesado debe solicitar autorización expresa a un tercero para incorporarlos en sus contactos y dicho tercero sólo se integrará a los mismos luego de consentir expresamente en ello, de lo que se desprende que sólo entre quienes así han consentido la información y sus comunicaciones es pública, no existiendo habilitación para que dicha información sea utilizada por otras personas (Sentencia de la Corte Suprema de Justicia rol 5322-2012, 2012: voto de minoría, considerando tercero; la cursiva es nuestra).

Conviene destacar el valor que le otorga el ministro Muñoz al consentimiento como factor determinante para configurar la frontera entre lo público y lo privado de una publicación en Facebook. Es el usuario, mediante expresión de su voluntad, el que permite a otro ingresar en ese espacio privado. Sin esa autorización, el acceso, registro o utilización de las comunicaciones constituye una afectación de la garantía de inviolabilidad e, incluso, podría configurar algunos de los delitos contra la privacidad contenidos en la legislación nacional.

De esta manera, la decisión del ministro $\mathrm{Muñoz}$ es coherente con el criterio del Tribunal Constitucional que sostiene que es necesario respetar y proteger «ese ámbito reservado de la vida, en el cual no es lícito penetrar sin el consentimiento del afectado» (Sentencia del Tribunal Constitucional rol 389-2003, 2003: considerando decimoctavo), el que

integra los derechos personalísimos o del patrimonio moral de cada individuo, los cuales emanan de la dignidad personal [...]. Por tal razón, ellos merecen reconocimiento y protección excepcionalmente categóricos tanto por la ley, como por los actos de autoridad y las conductas de particulares o las estipulaciones celebradas entre éstos (Sentencia del Tribunal Constitucional rol 389-2003, 2003: considerando vigésimo).

Lamentablemente, el voto de mayoría de la Corte Suprema pasó por alto el razonamiento del Tribunal Constitucional, que data del año 2003 y validó la obtención ilegítima de una comunicación que se realizó en un entorno privado.

Como se puede apreciar, la jurisprudencia constitucional ha tenido escasas ocasiones para referirse a las comunicaciones privadas electrónicas que se realicen por medios distintos al correo electrónico y, en particular, a través de las cada vez más populares redes sociales. Lamentablemente, de los pocos casos existentes, en Figueroa vs Prefecto Cautín, la mayoría de la Corte Suprema desaprovechó la oportunidad de aplicar las directrices interpretativas que ha desarrollado el Tribunal Constitucional respecto a la protección de las comunicaciones privadas, tal como correctamente resolvió el voto disidente.

A continuación, analizaremos la más común de las prácticas cotidianas de los usuarios de internet, la navegación. 


\section{Navegación por internet}

Buena parte de las acciones que realiza un usuario en internet son prácticas de comunicación personal que, como hemos visto, están amparadas constitucionalmente. Cabe entonces preguntarse si las otras actividades que se llevan a cabo cotidianamente - por ejemplo, la mera navegación, el uso de redes sociales y la publicación de contenidosgozan de algún tipo de protección. Nos centraremos en esta ocasión en la navegación.

La navegación en internet, esto es, la actividad mediante la cual una persona visita una determinada cantidad sitios de internet cada vez que se conecta, ya sea con fines personales, profesionales o comerciales, es un tipo de acción que, por las características técnicas de internet, suele dejar una cantidad importante de rastros o trazas del comportamiento del usuario. Así, por ejemplo, los prestadores de servicios de acceso a internet mantienen un registro de las veces que un cliente se conectó a la red, el tiempo de duración de la conexión, el número IP que se le asignó y, probablemente, una identificación del dispositivo electrónico que utilizó, información que recibe el nombre de «datos de tráfico». Por su parte, los proveedores de servicios de internet, como Google, Facebook, Twitter, también registran la actividad que realizan sus usuarios cada vez que utilizan sus servicios, almacenando además los contenidos e interacciones que generan con otros usuarios de la red.

Cada uno de estos registros permite construir perfiles de uso de determinada plataforma o servicio de cada usuario. Además, posteriores tratamientos de datos personales o cruces de datos permiten identificar hábitos, tendencias políticas, orientación sexual, opinión religiosa, etcétera, información cuya utilización indebida podría afectar el derecho a la vida privada de sus titulares, entre otros derechos.

Al respecto, el Tribunal Constitucional ha sostenido que todas las personas tenemos el derecho a circular anónima e indistinguiblemente de los demás, sin chequeos ni registros ni seguimientos o monitoreos sistemáticos, constantes o focalizados, que permitan husmear a qué lugares asiste, por dónde circula, cuál es el número de sitios que visitas, con quién, o con cuánta duración y frecuencia se producen las conexiones realizadas cuando se conecta a internet. Advierten que a partir de estos datos es posible inferir historiales que incluyen hábitos y patrones de conducta humana. Se puede inferir de esta interpretación que se reconoce a las personas un derecho al anonimato como objeto de protección constitucional fundado en la garantía del derecho a la vida privada (Sentencia del Tribunal Constitucional rol 1894-11, considerando vigésimo segundo).

Por su parte, la actividad que una persona lleva a cabo en internet forma parte del derecho a la vida privada porque

si bien esta red de informática mundial configura un espacio abierto a todos, los sitios visitados en un recorrido, así como los correos electrónicos y la mensajería instantánea allí producidas, revisten carácter confidencial (Sentencia del Tribunal Constitucional rol 1894-11, considerando vigésimo tercero).

Ambas interpretaciones - el derecho al anonimato y la confidencialidad de la nave- 
gación- son quizás los aportes más relevantes del Tribunal Constitucional en la aplicación expresa del estatuto de garantías constitucionales a la vida privada que se lleva a cabo en internet, en especial, a la navegación en la red (entendida como el registro de «sitios visitados en un recorrido» en palabras del Tribunal), gozando por tanto de protección constitucional, cuestión que debiera significar importantes efectos en la forma en que los tribunales ordinarios de justicia resuelvan, en lo sucesivo, los casos sometidos a su consideración.

Además, la interpretación restringe considerablemente el alcance de las medidas intrusivas de la vida privada que están expresamente establecidas en la ley, como, por ejemplo, las normas que regulan la retención de datos de tráfico de los usuarios de sistemas de comunicaciones.

Conforme vimos previamente, al protegerse la comunicación en sí misma, esto es «el mensaje» (continente y contenido) y los «datos de tráfico», como expresamente señaló el Tribunal

lo que esta garantía protege es la comunicación, cualquiera sea su contenido y pertenezca o no éste al ámbito de la privacidad o intimidad. El secreto se predica respecto de la comunicación. Por lo mismo, abarca el mensaje y los datos de tráfico (ruta, hora, fecha, sujetos, etc.) (Sentencia del Tribunal Constitucional rol 2153-11, considerando trigésimo primero; el énfasis es nuestro).

En nuestro sistema jurídico, la única norma que autoriza expresamente el acceso a los datos de tráfico de una persona está contenida en el artículo 222 del Código Procesal Penal, ${ }^{33}$ que obliga a las compañías que prestan servicios de telecomunicaciones a conservar «un registro, no inferior a un año, de los números IP de las conexiones que realicen sus abonados», registro que estará a disposición del Ministerio Público con el único objetivo de permitir la realización de medidas de interceptación de comunicaciones telefónicas u otras formas de telecomunicación, cuando se cumplan con los requisitos establecidos en el mismo artículo 222 del citado código, esto es:

33. Artículo 222.- Interceptación de comunicaciones telefónicas. Cuando existieren fundadas sospechas, basadas en hechos determinados, de que una persona hubiere cometido o participado en la preparación o comisión, o que ella preparare actualmente la comisión o participación en un hecho punible que mereciere pena de crimen, y la investigación lo hiciere imprescindible, el juez de garantía, a petición del ministerio público, podrá ordenar la interceptación y grabación de sus comunicaciones telefónicas o de otras formas de telecomunicación. [...]

LAs empresas telefónicas y de comunicaciones deberán dar cumplimiento a esta medida, proporcionando a los funcionarios encargados de la diligencia las facilidades necesarias para que se lleve a cabo con la oportunidad con que se requiera. Con este objetivo los proveedores de tales servicios deberán mantener, en carácter reservado, a disposición del Ministerio Público, un listado actualizado de sus rangos autorizados de direcciones IP y un registro, no inferior a un año, de los números IP de las conexiones que realicen sus abonados. La negativa o entorpecimiento a la práctica de la medida de interceptación y grabación será constitutiva del delito de desacato. Asimismo, los encargados de realizar la diligencia y los empleados de las empresas mencionadas en este inciso deberán guardar secreto acerca de la misma, salvo que se les citare como testigos al procedimiento." 
- que existan fundadas sospechas;

- de la comisión o preparación;

- de un hecho que merezca pena de crimen; y

- la investigación lo hiciere imprescindible.

Todo ello, previa autorización del juez de garantía competente.

Si no se cumple alguno de los requisitos establecidos en la ley, no existen posibilidades de acceder legítimamente a los datos de tráfico de una persona, por estar protegidos por la garantía de inviolabilidad de las comunicaciones privadas y el derecho a la vida privada, como ya hemos visto.

De esta manera, si el Ministerio Público quisiera acceder, por ejemplo, a los datos de tráfico de determinada persona, para investigar la comisión de un delito que no merezca pena de crimen, no estaría habilitado legalmente para acceder a esa información y requeriría siempre del consentimiento expreso de la persona afectada. Esto implica, además, que las empresas de telecomunicaciones que almacenan los datos de tráfico debieran exigir siempre, para salvar su responsabilidad civil y probablemente penal, el cumplimiento de los requisitos señalados y negarse a entregar la información cuando no se compruebe su estricta acreditación.

\section{Conclusiones}

Como pudimos apreciar, el derecho a la privacidad ha comenzado a enfrentar, cada vez más, nuevas formas de afectación o limitación fruto del desarrollo tecnológico y el proceso de digitalización de nuestra vida cotidiana. Ante este escenario, resultaba esencial analizar el contenido normativo del derecho a la vida privada propiamente tal y el derecho a la inviolabilidad de las comunicaciones, desde el enfoque de los usos que las personas realizan en internet.

La escasa doctrina existente no se había pronunciado mayormente sobre los alcances de la interacción entre el derecho a la privacidad y las tecnologías, a pesar de que - como vimos - las normas son tecnológicamente neutras y, por ello, la aplicación de las disposiciones constitucionales y legales no resultaban especialmente complejas.

Hemos argumentado que el derecho a la inviolabilidad de las comunicaciones privadas es un derecho fundamental autónomo e independiente de la protección que se brinda a la vida privada en la Constitución, y que dicha independencia tiene efectos en la extensión de la protección de las comunicaciones privadas, en especial, respecto a las comunicaciones electrónicas.

Asimismo, hemos sostenido que el alcance de la expresión "privada» utilizada en el numeral $5 .^{\circ}$ del artículo 19 es sustancialmente distinto - en tanto concepto formal que describe únicamente las comunicaciones donde el emisor singulariza a los destinatarios de ellas, con el propósito que solo ellos la reciban - al concepto de «vida privada» que utiliza el numeral $4 .^{\circ}$ de la misma disposición constitucional. 
Distinguir el derecho a la vida privada del derecho a la inviolabilidad de las comunicaciones privadas es fundamental para comprender el genuino alcance de la protección constitucional de las comunicaciones privadas, que - en nuestra opinión y como ya hemos anticipado- difiere formal y sustancialmente de la protección que se brinda a la vida privada.

Como pudimos apreciar, la jurisprudencia constitucional ha amparado de manera contundente las comunicaciones privadas que se verifican a través de correos electrónicos, aplicando en extenso el estatuto de inviolabilidad consagrado en el numeral $5 .^{\circ}$ del artículo 19 de la Constitución.

Respecto a las comunicaciones que se realizan a través de redes sociales, debemos primero distinguir si se trata de comunicaciones «abiertas»o «cerradas» para determinar si también les resulta aplicable dicho estatuto. Sin perjuicio de ello, en el caso de las comunicaciones abiertas, examinamos ciertos criterios que permitirían invocar la protección constitucional, cuestión que lamentablemente, la escasa jurisprudencia no ha sido capaz de resolver adecuadamente y, a partir de análisis formalistas, ha negado la debida protección que estas novísimas formas de comunicación merecen.

Por último, respecto a la navegación en internet, pudimos constatar que, en opinión del Tribunal Constitucional, el mero hecho de usar la red constituye un acto que pertenece al ámbito de la vida privada de las personas, protegido por el numeral $4 .{ }^{\circ}$ del artículo 19 de la Constitución Política.

\section{Referencias}

Álvarez Valenzuela, Daniel (2004). "La inviolabilidad de las comunicaciones electrónicas». Revista Chilena de Derecho Informático, 5: 191-202.

-. (2019). La inviolabilidad de las comunicaciones privadas electrónicas. Santiago: Lom. [En imprenta]

Anguita, Pedro (2007). La protección de datos personales y el derecho a la vida privada. Régimen jurídico, jurisprudencia y derecho comparado. Santiago: Jurídica.

BARros, Enrique (2010). Tratado de responsabilidad extracontractual. Santiago: Jurídica.

CAMACHO, Gladys (2014). «La protección de datos como frontera del derecho de acceso a la información en la legislación chilena». Revista de Gestión Pública, 3 (1): 73-93.

CeA, José Luis (2004). Derecho Constitucional Chileno. Tomo II: Derechos, deberes y garantías. Santiago: Ediciones Universidad Católica de Chile.

BCN, Biblioteca del Congreso Nacional (2008). Actas oficiales de la Comisión Constituyente. Tomo IV. Disponible en http://bit.ly/2rYDYlJ.

CoRral TAlCiani, Hernán (200oa). «Configuración jurídica del derecho a la privacidad I: Origen, desarrollo y fundamentos». Revista de Derecho (Pontificia Universidad Católica de Valparaíso), 27 (1): 51-79.

-. (20oob) «Configuración jurídica del derecho a la privacidad II: Concepto y delimitación». Revista de Derecho (Pontificia Universidad Católica de Valparaíso), 27 (2): 331-355. 
Figueroa, Rodolfo (2015). Privacidad. Santiago: Ediciones UDP.

López SANTAMARía, Jorge (1982). «Consideraciones sobre el derecho a la privacidad o al secreto de la vida privada». Revista de Derecho y Jurisprudencia y Gaceta de los Tribunales, 79 (3): 65-78.

Moнor, Salvador (2013). «Naturaleza jurídica de los correos electrónicos remitidos y recepcionados por funcionarios públicos. Jurisprudencia del Tribunal Constitucional». Revista de Derecho Público, 78 (1): 225-234.

Nieves Saldaña, María (2011). «The right to privacy. La génesis de la protección de la privacidad en el sistema constitucional norteamericano». Revista de Derecho Político (UNED), 85: 195-240.

Nogueira Alcalá, Humberto (2013). Derechos fundamentales y garantías constitucionales. Santiago: Librotecnia.

Novoa Monreal, Eduardo (1979). Derecho a la vida privada y libertad de información. Un conflicto de derechos. Ciudad de México: Siglo XXI.

QuezADA, Flavio (2012). «La protección de datos personales en la jurisprudencia del Tribunal Constitucional de Chile». Revista Chilena de Derecho y Tecnología, 1 (1): 125-147.

Rodríguez, Eduardo (2003). «El correo electrónico». Revista Chilena de Derecho Informático, 3: 193-209.

TAPIA, Mauricio (2008). «Fronteras de la vida privada en el derecho chileno». Revista Chilena de Derecho Privado, 11: 117-144.

UndurRaga, Verónica (2005). «La privacidad como bien jurídico». En Juan Varas Braun y Susan Turner Saelzer (coordinadores), Estudios de Derecho Civil: Código y dogmática en el sesquicentenario de la promulgación del Código Civil. Jornadas Nacionales de Derecho Civil, Valdivia. Santiago: LexisNexis.

VIAL, Tomás (2000). «Hacia la construcción de un concepto constitucional del derecho a la vida privada». Revista Persona y Sociedad, 14 (3): 47-68.

Vivanco, Ángela (1992). Las libertades de opinión y de información. Santiago: Andrés Bello.

-. (2006). «Estatuto constitucional de la libertad de expresión y los medios de comunicación social: derecho a la honra, inviolabilidad del hogar, libertad de conciencia y libertades de opinión y de información». En Curso de Derecho Constitucional. Aspectos dogmáticos de la Carta Fundamental de 1980. Santiago: Ediciones Universidad Católica de Chile.

ZweIgert, Konrad y Hein Kötz (2002). Introducción al derecho comparado. Ciudad de México: Oxford University Press.

\section{Agradecimientos}

Agradezco la colaboración en la investigación de los ayudantes Carlo Benussi Díaz y Máximo Saavedra Díaz y las observaciones del profesor Alberto Cerda Silva. 


\section{Sobre el autor}

Daniel Álvarez Valenzuela es abogado, licenciado en Ciencias Jurídicas y Sociales, Diplomado en Derecho Informático, Magíster en Derecho Público y Doctorando en Derecho, todos por la Facultad de Derecho, Universidad de Chile. Socio de Ciberseguridad Humana. Fundador y Editor General de la Revista Chilena de Derecho y Tecno-logía.Su correo electrónico es dalvarez@derecho.uchile.cl. 
La Revista de Derecho Público es publicada, desde 1963, dos veces al año por el Departamento de Derecho Público de la Facultad de Derecho de la Universidad de Chile. Su propósito es la difusión de los avances del derecho público nacional e internacional y la socialización de artículos de investigación inéditos tanto de la comunidad académicas nacional e internacional.

DIRECTORA

Ana María García Barzelatto

SECRETARIO DE REDACCIÓN

Felipe Peroti Díaz

(fperoti@derecho.uchile.cl)

SITIO WEB

revistaderechopublico.uchile.cl

CORREO ELECTRÓNICO

publico@derecho.uchile.cl

LICENCIA DE ESTE ARTÍCULO

Creative Commons Atribución Compartir Igual 4.0 Internacional

La edición de textos, el diseño editorial

y la conversión a formatos electrónicos de este artículo

estuvieron a cargo de Tipográfica

(www.tipografica.cl). 